\title{
FORMAÇÃO EM SAÚDE MENTAL DE ACADÊMICOS DO CURSO DE MEDICINA
}

\section{MENTAL HEALTH EDUCATION OF ACADEMICS THE MEDICINE COURSE}

\author{
Luciana Dallazen Bombardelli \\ Carlos Alberto Severo Garcia Jr. \\ Giovani Tesser \\ Marcos Aurélio Maeyama
}

\section{RESUMO}

A saúde mental tem estado em pauta e está no centro das atenções do século XXI, dada a sua prevalência e importância no bem-estar geral das pessoas. Nesse sentido, a formação médica na área de saúde mental, assume papel importante para contemplar profissionais capazes de lidar com o sofrimento emocional das pessoas. Assim, o objetivo deste trabalho foi de caracterizar a formação em saúde mental do curso de Medicina da Univali, identificando suas potencialidades e fragilidades. $O$ estudo de abordagem qualitativa realizou coleta de dados a partir de entrevistas semiestruturadas com três professores e três alunos do curso. Para análise de dados foi utilizada a técnica de análise de conteúdo temático. A partir da leitura e análise das entrevistas, emergiram quatro categorias relacionadas à formação em saúde mental: organização curricular - com pequena exposição em atividades de saúde mental ao longo do curso e deficiência no processo avaliativo como limitadores no processo formativo; estrutura emocional dos estudantes - fragilidade com a necessidade de suporte emocional e potência pela possibilidade de humanização, necessária para a prática em saúde mental; transferência, contratransferência e projeção - com necessidade de acompanhamento psicológico para o exercício da prática em saúde mental; subjetividade da saúde mental - dificuldade de assimilação pela lógica hegemônica objetiva do modelo tradicional biomédico. Nesse sentido o estudo aponta para a necessidade de uma visão diferente na organização do curso, que transcenda a estrutura curricular focado na disciplina, para o cuidado com o estudante de medicina.

Palavras-chave: Saúde Mental. Educação Médica. Currículo.

\begin{abstract}
Mental health has been on the agenda during the mid of the 21st century, given its prevalence and importance for the general well-being of people. In this context,
\end{abstract}


medical training in the area of mental health took important role to contemplate professionals that had to be capable of dealing with the emotional suffering of people. Thus, the objective of this work was to characterize the mental health training of the Univali medical course and identifying its potentials and weaknesses. The qualitative study collected data from semistructured interviews with teachers and students of the course. For data analysis, the thematic content analysis technique was used. From the reading and analysis of the interviews, four categories related to mental health training emerged: curricular organization - with a small exposure in mental health activities throughout the course and deficiency in the evaluation process as limiters in the formative process; emotional structure of students - fragility with the need for emotional support and power for the possibility of humanization, necessary for practice in mental health; transference, countertransference and projection - with the need of psychological counseling for the practice of mental health practice; subjectivity of mental health - difficulty of assimilation by the objective hegemonic logic of the traditional biomedical model. In this sense, the study points out that there is need for a more organic vision in the organization of the course, which transcends the curricular structure focused on the discipline, to care for the medical student.

Keywords: Mental Health. Medical Education. Curriculum.

\section{INTRODUÇÃO}

De acordo com as Diretrizes Nacionais Curriculares (DCN) do curso de Medicina, o profissional médico deve ter uma formação generalista, humanista, crítica e reflexiva ${ }^{1}$. Dentro de suas competências, inclui o cuidado de indivíduos com transtornos mentais.

A saúde mental tem estado em pauta e está no centro das atenções do século XXI. Cada vez mais é necessário que os profissionais da saúde possam cuidar das pessoas respeitando a sua singularidade, contexto e sofrimento.

Ao longo das últimas duas décadas ocorreram significativas reorientações da atenção aos pacientes com transtornos mentais, dadas a criação e ampliação de serviços de cuidado, buscando substituir a lógica exclusivamente hospitalocêntrica por um modelo de atenção psicossocial, diversificando as formas de terapêutica e criando novos cenários de atuação².

A relevância do presente estudo reúne três dimensões: prática, científica e educacional. A primeira está atrelada ao interesse pelo perfil de formação do futuro profissional médico, relacionado ao preparo para lidar com a saúde mental de seus 
pacientes, uma vez que esses problemas estão cada vez mais no cotidiano dos serviços de saúde, independente de cenário ou especialidade. A importância científica refere-se à possibilidade de publicizar material de pesquisa para futuros trabalhos que levem em conta a formação médica em saúde mental. Por fim, a relevância educacional, engloba a detecção das possíveis estratégias de ensino, conteúdos programáticos, inserções em cenários práticos e avaliações no ensino da disciplina aos discentes, para possibilitar, a qualificação do processo de ensino-aprendizagem relacionado a saúde mental.

Assim, o objetivo deste trabalho foi de caracterizar a formação em saúde mental do curso de Medicina da Univali, identificando suas potencialidades e fragilidades, para reflexão e ação de possíveis melhorias na educação médica.

\section{METODOLOGIA}

Trata-se de um estudo qualitativo e prospectivo e, de acordo com Minayo (2008), esse tipo de estudo se divide em três etapas: definição da amostragem, de modo que ela possibilite abranger a totalidade do problema investigado em suas múltiplas dimensões; a coleta de dados, definição das técnicas a serem utilizadas para a pesquisa de campo; e organização e análise de dados ${ }^{3}$.

A escolha pela abordagem qualitativa se deve pelo fato dela responder muito mais aos significados das coisas do que a quantificação numérica de variáveis ${ }^{3}$, indo ao encontro do objetivo deste trabalho que é de caracterizar a formação em saúde mental do curso.

Para alcance do objetivo, a coleta de dados foi realizada por meio de entrevistas semiestruturadas, que permitiram maior aprofundamento de questões relevantes para a pesquisa.

Para maior amplitude na descrição, explicação e compreensão do estudo, foi utilizada a técnica de triangulação ${ }^{3}$ com coleta de dados realizadas com três docentes do curso de medicina da área de saúde mental (representam a totalidade de professores da área atuantes no momento da coleta de dados), e três alunos do décimo segundo período, escolhidos de forma aleatória por meio de sorteio. A previsão de amostra inicial era de seis acadêmicos, porém, diante da 
recusa/dificuldade de agendas dos elegíveis, e por conta do cronograma proposto para a pesquisa, ela se restringiu aos que aceitaram participar dentro do período estabelecido para coleta de dado. A escolha por alunos do décimo segundo período foi realizada de forma intencional, pelo fato de estes já estarem no último período do curso, e que, portanto, em teoria, poderiam responder melhor a questão da formação em saúde mental do curso em questão.

Todas as entrevistas foram gravadas e transcritas na íntegra. Para análise de dados foi utilizada a técnica de análise de conteúdo temático, que a partir do processo de leitura exaustiva, foram escolhidas unidades de registro e posteriormente agrupados em categorias ${ }^{3}$ relacionadas à formação em saúde mental.

A Análise de Conteúdo é elaborada como uma prática que se pretende a construção de um plano de significados, trata-se de uma tentativa em alcançar diretamente o que haveria por trás do é expressado no texto, ou neste caso, na entrevista. Este método tem como objetivos a minimização da incerteza e a otimização do conteúdo da leitura de maneira que se torne enriquecida ${ }^{4}$.

Este trabalho foi aprovado pelo Comitê de Ética em Pesquisa (CEP) da Universidade do Vale do Itajaí no Parecer no 2.777.211. Esta pesquisa não contou com nenhuma fonte de financiamento e os autores não declaram nenhum tipo de conflito de interesse.

\section{RESULTADOS/ DISCUSSÃO}

Para facilitar a apresentação dos resultados, os docentes da disciplina entrevistados receberam individualmente nomes de árvores frutíferas (Jabuticabeira, Pessegueiro e Macieira), enquanto os discentes receberam nomes de frutos (Jabuticaba, Pêssego e Maçã).

Foram identificadas quatro categorias temáticas relacionadas à formação em saúde mental: 1) organização curricular; 2) estrutura emocional dos estudantes; 3) transferência, contratransferência e projeção; 4) subjetividade da saúde mental. 


\section{Organização Curricular}

Os acadêmicos de medicina da UNIVALI na matriz 2, dentro da organização curricular de disciplinas, têm o primeiro contato formal e direto com a área de saúde mental no sexto período, novamente no sétimo e finalmente no décimo período.

No sexto período as aulas apresentam uma visão geral e da psicodinâmica do funcionamento da mente humana, com participação significativa por parte dos alunos. O método de ensino é um compêndio entre aula expositiva, discussão de textos, filmes e seminários.

Vamos entender um distúrbio de personalidade, né? Então vamos entender como que ele se formou na mente daquela pessoa e como ela pode estar desenvolvendo ferramentas para estar lidando com a problemática dela. (Jabuticabeira)

No sétimo período, os acadêmicos entram em uma aula mais tradicional relacionada diretamente com a psiquiatria em si. Os professores utilizam algumas técnicas como aula expositiva, sala de aula invertida e estudos de caso, sempre tentando manter um ambiente dinâmico de participação de todos da turma.

Ao chegar no décimo período, os acadêmicos têm a oportunidade de realizar consultas especificamente voltadas às demandas psiquiátricas, e é a única vez durante toda a formação acadêmica que eles conseguem ter o acompanhamento prático do professor psiquiatra.

Eles participam de forma prática no internato em saúde mental, no qual os alunos atendem os pacientes do ambulatório de psiquiatria da própria instituição e depois buscam 0 aconselhamento/ direcionamento dos professores. [...] São as 7 semanas de contato com a psiquiatria, dentro da Medicina de Família. (Pessegueiro)

Esse ambulatório em saúde mental é um "apêndice" da disciplina de internato em medicina familiar e comunitária (estágio que está presente em todos os semestres do internato), e nos momentos de queixas psiquiátricas relacionadas às consultas de rotina nos períodos subsequentes, os alunos obtêm aconselhamentos e acompanhamento de médicos generalistas. 
Esta matriz curricular ainda é hiperdependente do funcionamento da medicina da família, então como a gente estava inserido na medicina da família, era um médico generalista [pausa] do modelo de assistência de saúde da família a ver os casos de saúde mental... é... puxando pro ambulatório exclusivo de psiquiatria é um ambulatório onde os alunos conseguem observar como um especialista age nas questões psiquiátricas. (Pessegueiro)

Esse curto espaço de aprendizado interfere significativamente na formação dos acadêmicos de medicina em saúde mental, e isso foi um achado unânime entre os professores e os alunos, especialmente por parte dos acadêmicos, que inclusive relataram a sua sensação de despreparo em relação à demanda que encontrarão no futuro em seus respectivos ambientes de trabalho.

Pouca quantidade de aulas em relação com o que eles encontram na prática médica... então sentem-se muito pouco capazes... acho que as últimas turmas foram muito difíceis porque eram turmas muito grandes e tiveram muito pouco tempo com o paciente psiquiátrico... acho que eles não se sentem bem preparados para lidar com isso no dia a dia. (Pessegueiro)

Eu aumentaria a área de saúde mental, pelo menos um dia da semana um dia inteiro ou duas tardes... acho que tinha que ter um pouco mais... acho que a gente teve muito pouco. (Pêssego)

Luckesi (2011) discorre sobre a parte prática da universidade, afirmando que a própria experiência prática vai delineando uma nova forma de ser e agir, construindo para si mesmo um modo constante de agir ${ }^{5}$. Assim a experiência prática em saúde mental, a partir do exercício de interação com os pacientes e familiares, deve ser propiciado em quantidade e qualidade que permitam a segurança, para o futuro médico, no agir em saúde mental.

Quanto aos métodos de avaliação, os professores utilizam provas objetivas com algumas questões subjetivas, seminários, construção de mapas mentais e, no internato, são avaliados com uma nota comportamental baseada em seus atendimentos. Nesse sentido, os três acadêmicos entrevistados consideraram baixa "cobrança" por parte dos professores nas avaliações.

A saúde mental te exigir muito estudo? Acho que não... acho que foi uma matéria assim que a gente estudou... eu estudei assim 
porque se eu não tivesse acesso àquelas doenças, eu não teria em outro momento... eu acho que é uma disciplina assim muito única... e acho que o jeito de cobrar eu até gostava das provas (Pêssego)

A maior limitação quanto a avaliação talvez não esteja na falta de "cobrança", mas principalmente quanto ao seu caráter. Dois dos três alunos entrevistados relataram em seus depoimentos sobre uma carência que encontraram na forma de avaliação dos professores, especialmente na parte prática da disciplina.

No internato eu não sei exatamente como foi a avaliação, porque a gente não teve um bom retorno no final, um feedback no final do ambulatório para ver o que a gente evoluiu. (Jabuticaba)

No estudo de Zimmermann (2019), salienta-se que, a visão do docente relativa à complexidade e à profundidade que 0 ato avaliativo encerra, possibilita 0 aprendizado à medida que a avaliação não é apenas um resultado numérico, mas também uma oportunidade de crescimento a partir dos próprios erros ${ }^{6}$. Esse aprendizado se faz por meio da conjunção de fatores, dentre eles, corrigir os erros e propor questionamentos sobre seu desempenho, o que vai além de transmitir experiência, conhecimento, habilidades e atitudes.

Outro ponto ressaltado no presente estudo foi quanto à forma como os atendimentos são realizados, que não permitem que os professores consigam ter uma visão completa da atuação dos acadêmicos durante o estágio, devido ao pouco contato com a disciplina de um modo geral e também, por serem consultas em duplas, dificultando uma avaliação mais singular. Isso faz com que o aluno não consiga corrigir grande parte dos erros cometidos, o que também se traduz em um aspecto negativo da sua formação.

Acho que os professores não percebem nosso esforço, [...] às vezes não é tu que passou o caso. (Pêssego)

Um dos acadêmicos constata que um dos motivos de dificuldade no atendimento psiquiátrico é o fato de ele nunca ter acompanhado uma consulta inteira de psiquiatria, portanto não sabe como se portar/ abordar aquele paciente que está ali na sua frente. 
É muito difícil sair do zero! Como é que a pessoa vai saber? É como você falar: faz aí, auxilia uma apendicectomia e você nunca viu! Mas pera aí! Como vou auxiliar se eu nunca vi? Eles acabam, acabam nunca tendo uma noção. (Maçã)

Ao relatar a experiência de ensino-aprendizagem da anamnese psiquiátrica no curso de Semiologia em Psiquiatria na Unesp, um estudo utilizando a inversão de papéis como método pedagógico afirmou que essa técnica pode auxiliar os estudantes de Medicina no aprendizado da anamnese psiquiátrica, assim como no desenvolvimento da empatia, habilidade essencial à prática médica de boa qualidade. A técnica é baseada em um estudo autônomo da apostila de propedêutica psiquiátrica pelos alunos e, logo após, alterna-se o papel de paciente e de médico pelos alunos, com temas ambulatoriais e hospitalares. Após isso, acontece uma discussão das anamneses realizadas, com auxílio dos professores para identificar as fragilidades e os pontos positivos das entrevistas ${ }^{7}$.

Além das atividades existentes, a experiência em estágio optativo de um dos alunos, realizado na Emergência de um Hospital que possui atendimento em porta específico para psiquiatria e com ala psiquiátrica, aponta para outros cenários importantes para a formação em saúde mental.

Aqui na universidade, no ambulatório, foi meu único contato prático com pacientes (psiquiátricos), já com diagnóstico e os pacientes já estavam mais compensados, ou era mais retorno para renovação de receita ou era algo assim. Não atendemos pacientes em crise. Eu pelo menos não. (Jabuticaba)

A formação em saúde mental na instituição apresenta uma carência na diversificação de cenários de prática, que se limita às consultas ambulatoriais. Ela acaba não contemplando o contato com as emergências psiquiátricas, o que é difícil de mudar levando em consideração a hiperdependência do hospital escola que não possui ala psiquiátrica.

Eu não acabei vendo muitos casos tipo surto, pós-tentativa de suicídio... então eu achei que faltou assim... até quando eu vi agora alguns casos eu fiquei tipo ah não sei como abordar, mas... acho que é isso assim. (Jabuticaba) 
Ainda que a formação deva estar voltada para o profissional generalista, a diversificação de cenários de prática, apontadas pelas $\mathrm{DCN}$, é no sentido de contemplar a formação de um profissional integral, que compreenda as diferentes necessidades das pessoas, e para tanto, deve estar preparado para atuar, nos diferentes níveis de atenção ${ }^{8}$.

\section{Estrutura Emocional dos Estudantes}

Os três professores deram ênfase importante em seus discursos sobre a existência de um interesse notório por parte dos acadêmicos de medicina pelos seus próprios estados mentais. Grande parte dos alunos, à medida que o tempo passa, agrega conhecimento a respeito dos transtornos psíquicos, se enxerga adoentado e carente de entendimento sobre si mesmo, e, portanto, demonstra-se interessado no conteúdo exposto.

Muito comum os alunos pedirem algum tipo de orientação, algum encaminhamento, ficar bem à vontade para dividir algumas coisas comigo, e sempre que quando a turma não estava indo muito bem de relacionamento, eles vinham me procurar para eu ajudar. (Jabuticabeira)

Eu não sei se eles se interessam pela aula, acho que existe uma demanda clínica de consultas deles, entendeu? Isso eu acho que sim, mas não sei se tem uma demanda de eu quero aprender para ajudar os outros, entendeu? (Macieira)

Acho que alguns alunos se interessam principalmente a partir das próprias dificuldades... Então, a saúde mental tem um certo mistério. (Pessegueiro)

Observa-se a partir disso que existe uma real preocupação dos docentes em relação à saúde mental dos seus alunos, e, especialmente no sexto período, existe um espaço durante as rodas de conversa para que os alunos expressem seus sentimentos, a fim de encontrar uma resolução para parte das questões internas desta turma.

Eu penso que vai ter turma mais aberta para isso e turma menos aberta.... Turmas mais fechadas eu penso que é mais 
preocupante. O ideal é a que expressa sentimento para gente poder explorar isso né. (Jabuticabeira)

Eu penso que alguns já vem com uma certa não defesa. (Jabuticabeira)

Corroborando com essa lógica, outro professor afirma que vem observando ao longo dos anos uma dificuldade crescente dos acadêmicos em se deparar com problemas psicológicos das outras pessoas, como se estivessem cada vez menos aptos a lidar com o sofrimento alheio.

Chama a atenção a menor disponibilidade dos acadêmicos de conseguir se deparar com o sofrimento psíquico da outra pessoa, quando o prejuízo significativo que tem uma doença crônica na vida da pessoa, o prejuízo na vida familiar, na vida de trabalho, nas relações, e o quanto é difícil aguentar [pausa] pouca interferência em questões que não são reversíveis... situações assim, eu acho que chama a atenção por cada vez vem menos preparados para a vida, para conseguir tolerar isso. (Pessegueiro)

Este crescente despreparo emocional dos acadêmicos relatado pelo professor, é reflexo da própria sociedade contemporânea. Já no início deste século, segundo dados da Organização Mundial de Saúde, transtornos mentais como depressão, abuso de álcool, transtorno bipolar e esquizofrenia se encontram entre as 20 principais causas de incapacidade ${ }^{9}$. Santos e Siqueira (2010) analisaram estudos sobre a prevalência de transtornos mentais na população adulta brasileira e verificaram que as taxas variam de 20 a $56 \%$, e os transtornos mais prevalentes indicados nos estudos são os de ansiedade, de humor, os somatoformes e o abuso de álcool ${ }^{10}$.

É diante dessa perspectiva que esse assunto vem entrando em pauta e é objeto de estudo em diversas universidades, e são preocupantes os achados epidemiológicos. Cada vez mais observa-se a verdadeira necessidade de acompanhamento psicológico desses acadêmicos, bem como de médicos formados, como sugere o estudo de Voltmer et al. (2010), que aponta que estudantes especificamente de Medicina tiveram escores significantemente menores de 
qualidade de vida relacionada com a saúde mental e física quando comparados com um grupo referência de jovens adultos ${ }^{11}$.

Por outro lado, como comentado por dois dos professores entrevistados, essa mudança no perfil do aluno de medicina e do médico, teve um aspecto positivo importante, pois hoje notoriamente procuram mais se conhecerem e buscarem uma evolução, perdendo-se assim aquela imagem de médico super-herói, inabalável. Um dos professores enfatiza o quão é importante e positiva essa característica, que por mais que eles pareçam mais "frágeis", estão questionando algo que era simplesmente ignorado, e buscando a partir disso uma solução.

Essa observação é ainda mais interessante quando levamos em consideração o perfil do estudante de medicina de antes das mudanças nas diretrizes nacionais em 2014, o que revela o quanto isso vem mudando com o passar dos anos. Ao escolherem a carreira médica, muitos estudantes são movidos pelo desejo de curar, ajudar ou salvar. Durante a graduação, no encontro com o paciente, essas expectativas afloram. Era demasiadamente comum no curso de medicina que, ao se deparar com situações que colocam em xeque sua resiliência, o estudante acaba negando sua própria subjetividade, em especial a expressão de seus sentimentos ${ }^{12}$.

Eu acho que é uma geração que está mais sensibilizada para as coisas do mundo mental. Então tenho tido boas notícias nesse sentido, muito boas notícias... Acho que temos uma geração de médicos bem diferente de outras gerações, mas bem diferentes... Começa que assim, se você pegar médicos de 30 anos atrás, nenhum deles buscou terapia entendeu... já trabalharam tanto na vida, já casaram 3, 4 vezes... Com uma mão construíram e com outra jogaram fora... [...] se eles não cuidarem da cabeça deles, tudo isso se perde... Fica bem claro isso! (Jabuticabeira)

Não se vê mais um aluno de medicina como algo blindado, [...] como as coisas abalam esses alunos, as características das pessoas que estão no curso de medicina, então se pressupõe algo a mais em relação a isso. (Pessegueiro)

Um dos grandes riscos que tradicionalmente os médicos correm é de adoecerem com a Síndrome de Burnout que, segundo Maslach e Jackson (1996) é uma "síndrome" multidimensional constituída por exaustão emocional, desumanização e reduzida realização pessoal no trabalho ${ }^{13}$. Com um acadêmico que tem ênfase na sua formação para ter um perfil mais humanizado e com um olhar 
voltado à própria saúde mental, os riscos de acometerem-se por essa doença são minimizados ${ }^{14}$.

A formação em saúde de um modo geral vem sofrendo mudanças ao longo dos anos, e cada vez mais se contempla não apenas uma visão centrada na doença, mas uma visão holística sobre o indivíduo. Reconhecem-se os avanços proporcionados pela tecnologia e pelo conhecimento científico, contudo a formação humanística já foi reconhecida como imprescindível para seu modo de aplicação. Hoje em dia, a capacidade de sentir empatia pelos pacientes, por exemplo, é considerada um dos pilares da boa prática médica, e a constante abordagem deste tema nas instituições, está corroborando com esse novo perfil do acadêmico de Medicina ${ }^{7}$.

Além disso, é diante dessa perspectiva que, com o aumento da prevalência e gravidade dos transtornos mentais nas populações brasileira e mundial, a área de saúde mental passou a ter papel fundamental na formação do médico generalista. Cada vez mais é requerido pela população de modo geral, mais atenção para a saúde mental, pois o que acontece com os acadêmicos de medicina de sentirem-se mais adoecidos com o passar dos anos, acontece também com a sociedade como um todo, trazendo novos desafios para as instituições de ensino superior ${ }^{15}$.

Além disso, é importante não só o autoconhecimento, mas também ter uma atenção ao cuidado em saúde mental.

A saúde mental mesmo dos alunos é uma característica imprescindível; é fundamental para uma pessoa que lida com pessoas é ser uma pessoa saudável mentalmente né, o mínimo que ela pode fazer é se conhecer, fazer uma boa terapia. (Jabuticabeira)

Assim como acontece com os psicoterapeutas, os acadêmicos de psiquiatria também são considerados um grupo de risco em manifestar problemas psicológicos devido ao seu trabalho com o sofrimento humano. Por este motivo, é necessário que os acadêmicos desenvolvam práticas de autocuidado como forma de prevenir o desgaste no local de trabalho ${ }^{16}$. Motivados por esta situação, Guerra et al. (2008) desenvolveram a Escala de Comportamentos de Autocuidado para Psicólogos Clínicos (EAP) que visa apoiar a mensuração do construto através de um questionário 
de como se sentem esses terapeutas, o que poderia também auxiliar na formação em saúde mental dos acadêmicos de medicina ${ }^{17}$.

Os alunos destacam que, ao longo do curso, quando começam a se deparar com momentos que fogem do controle, perdem ainda mais a sua estrutura emocional, demonstrando a importância do apoio emocional como parte de seu cuidado e autocuidado.

A terapia e a vida acadêmica, você consegue crescer, amadurecer. [...] Eu acho que todo mundo deveria ter oportunidade de fazer porque a gente cresce. (Maçã)

Todo mundo acaba ficando cansado, estressado também, então você tem que cuidar de si para lidar com problemas dos outros... porque se você tiver transbordando, e não tiver um bom emocional, então acho que acaba refletindo de forma no trabalho. (Jabuticaba)

Isso te ajuda a tu ser uma pessoa mais feliz. Tu ter mais saber, mais de si próprio, se conhecer mais, quando consegue resolver seus problemas, o maior beneficiado é você mesmo. A medicina e um curso que exige muito de ti... Existe muita pressão dos pais, da sociedade, dos teus colegas, dos professores, é muita cobrança... Então tu não tem muito tempo pra si próprio, quando tu tens uma terapia é um momento teu que tu está aí pra evoluir algo de ti, se dando um presente. (Pêssego)

Nesse sentido, seria interessante que a própria faculdade oferecesse algum tipo de acompanhamento não só durante o contato com saúde mental, mas desde o início da faculdade, a fim de preparar esses acadêmicos para um melhor aproveitamento da disciplina e do curso.

\section{Transferência, Contratransferência e Projeção}

Dentro da psiquiatria e do estudo da saúde mental de um modo geral, há o entendimento de que a nossa percepção sobre o nosso ambiente reflete basicamente o conteúdo da nossa própria mente, e, a partir disso, acredita-se que o profissional que ambiciona adentrar a mente de outrem para manejar possíveis patologias deve, no mínimo, conhecer-se para saber separar o que é o paciente e o que é ele mesmo. 
Diante dessa perspectiva, obtivemos com resposta por parte dos professores com unanimidade, que uma das maiores dificuldades do ensino de saúde mental no curso é a imaturidade desse conceito e do autoconhecimento por parte dos acadêmicos, que acabam distorcendo a realidade do paciente, ou comovendo-se mais do que deveria por projetar seus sentimentos exageradamente.

Me chama muita atenção a dificuldade deles atenderem, com relação a separar o que é do paciente e o que é deles, [...] tem que ter tratamento pessoal para saber como atender os outros. Acho que isso é uma característica importante, é o aluno ter consciência de algumas limitações ou de alguns problemas deles, para isso não atrapalhar no atendimento. Então ter contato com a sua própria saúde mental é um pré-requisito, eu imagino, para fazer um bom trabalho. (Macieira)

Os professores, por mais que observem que existe um avanço em relação a esse processo ao longo do tempo (também pelo fato de os médicos e acadêmicos de medicina estarem se permitindo mais adentrar em seus aspectos mentais), ainda possuem uma visão pessimista, e acreditam que ainda demanda muito tempo esta mudança para atingir um padrão próximo do ideal.

O quanto que eu vou conseguir ensinar que as pessoas identifiquem que aquilo é um problema, uma patologia, partindo do pressuposto que todos vão sentir determinadas coisas.... Acho que esse é o desafio maior. (Pessegueiro)

Os acadêmicos entrevistados também retrataram esta dificuldade, sendo que os três entrevistados têm o entendimento da necessidade de se conhecer para conseguir fazer um atendimento adequado, embora sintam que precisam melhorar nesse aspecto.

Se tu não sabe lidar, tipo... tu internaliza muito do que o paciente te passa, então tem vezes, que eu fiquei com raiva do paciente. (Pêssego)

Tu tem que estar muito bem assim, tem que estar em busca primeiramente da tua própria saúde mental para conseguir ajudar o outro. (Jabuticaba) 
O entendimento acerca do tema pelos acadêmicos é de extrema importância, pois, a contratransferência, por exemplo, é considerada como uma ferramenta que auxilia na compreensão do paciente quando bem estabelecida. Ela é utilizada como recurso terapêutico, mas seu uso suscita cuidados já que a detecção é tão sutil. Raiva, irritação e impotência são consideradas como sentimentos contratransferenciais de difícil manejo, assim como aqueles causados por pacientes com transtornos de caráter, perversão sexual e dependência química. Por isso, todo terapeuta que se sujeita a analisar a mente de outra pessoa, precisa entender que os sentimentos e significados inconscientes do que ocorre entre a dupla, depende da pessoa real do psicoterapeuta, que também atravessa todo o processo analítico ${ }^{18}$.

Por outro lado, sabe-se que os analistas reconhecem que descrever o conceito de contratransferência é uma tarefa muito complexa até para eles, e que o reconhecimento dessas questões demanda tempo e muita dedicação. Neste entendimento, está em jogo identificações tanto do paciente, quanto do terapeuta, e por este motivo, o foco atual está naquilo que uma dupla produz entre si e não o que cada um produz separadamente ${ }^{18}$.

\section{Subjetividade da Saúde Mental}

Outra dificuldade encontrada pelos docentes é conseguir fazer com que o acadêmico, que vem de uma didática que estimula o pensamento objetivo, buscando doenças orgânicas com recursos tecnológicos de imagens e exames laboratoriais, entenda e acredite na subjetividade que implica a psique humana.

Desafio é fazer os alunos compreenderem algo que é abstrato... Eu acho que isso é bastante difícil porque eu não tenho como provar nada, falo do funcionamento da mente, algo que objetivamente não existe, existe por funcionar, mas eu não tenho como provar. (Macieira)

Essa objetividade com que os alunos de medicina estão mais adaptados dialoga com a questão do modelo biomédico baseado no cientificismo. Cada vez mais emergente é a questão da humanização da medicina, que desata essas ataduras que limitavam o profissional médico a um interrogatório biológico em detrimento de uma 
visão holística do indivíduo. A partir disso, surge a ideia do pensamento ecológico, que quando aplicado ao campo da saúde será, então, aquele que, não rejeitando ou subestimando o papel da biomedicina, Ihe reconhece, todavia, a incompletude, considerando a urgente necessidade de a colocar em interação e diálogo horizontal com outras formas de saber. Posto isso, um passo fundamental na edificação de uma ecologia de saberes na área da saúde residirá, antes de tudo, na desconstrução do "privilégio epistêmico" da biomedicina ${ }^{19}$.

Os outros dois professores também relataram sobre as dificuldades que encontram neste sentido:

No curso de medicina, vocês seguem uma espécie de roteiro... examina, faz um diagnóstico de exames, e na saúde mental não existe isso. Então para as pessoas que precisam lidar com coisas concretas e ter tarefas, elas sofrem muito com a disciplina de Saúde Mental. (Jabuticabeira)

$\mathrm{Na}$ faculdade de medicina é uma dificuldade um pouco maior de entendimento do mundo psíquico. Acho que uma das maiores dificuldades é tornar uma coisa que é subjetiva em algo objetivo. (Pessegueiro)

Isso pode ser justificado pelo fato do ingresso no curso de Medicina requerer a transformação precoce de adolescentes em profissionais, e o acadêmico se baseia demasiadamente em protocolos por medo do erro, e, portanto, o acaba se tornando dependente dos padrões pré-estabelecidos da prática médica ${ }^{14}$.

Este entendimento dos professores é comprovado também a partir do depoimento de um dos alunos, que relata sobre a dificuldade que encontrou na prática e no estudo da saúde mental:

Eu tenho um pouco de dificuldade em trabalhar essa parte mais indireta, mais subjetiva... Eu tenho um jeito muito assim de na medicina, muito às vezes, objetivo, ainda mais com a pessoa que eu não conheço, eu acabo ficando intimidada. Eu realmente quero fazer o meu melhor para essa pessoa porque eu me importo, mas eu não me sinto com ferramentas internas para ajudar uma pessoa assim. (Jabuticaba)

O estudo de Balduíno et al. (2012) aponta que a fixação excessiva do estudante ao roteiro compromete a dinâmica inerente ao processo de encontro com o paciente, 
tornando a entrevista rígida, assumindo às vezes o caráter de um interrogatório maçante, o que impede uma comunicação mais plena, fluente e empática ${ }^{20}$.

Se os estudos apontam que a entrevista focada nas perguntas induz os estudantes a ignorarem sua habilidade de comunicação, passando a fazer perguntas fechadas, direcionadas apenas às informações clínicas, fica o questionamento, se não é a própria rotina de outras disciplinas, que cria esse perfil de acadêmico demasiadamente objetivo?

\section{CONSIDERAÇÕES FINAIS}

Os resultados do estudo demonstram que a formação em saúde mental é dependente, como em qualquer outra disciplina ou área, de uma consistente organização curricular. Porém, outros fatores externos - que também devem ser pensados pelo aparelho formador - influenciam no desenvolvimento da formação para o trabalho em saúde mental, como a fragilidade emocional dos estudantes, os processos transferenciais, contratransferenciais e de projeção, e a própria subjetividade da saúde mental, em confronto com a objetivação vista na área da saúde.

A alta prevalência e o aumento crescente de transtornos mentais que assolam a sociedade contemporânea colocam para a classe médica e para a área da saúde um grande desafio, pois independente da especialidade escolhida, os futuros pacientes virão com alguma carga emocional, que invariavelmente terá influência na condução do acompanhamento/tratamento de outros problemas de saúde.

Nesse sentido, a formação do médico, deve contemplar um preparo adequado para o manejo em saúde mental, independente da especialidade.

Para tanto, a sugestão no nível de organização curricular é que o tempo de exposição seja suficiente para que o acadêmico possa não apenas acompanhar atendimentos, mas realizar atendimentos e identificar os desdobramentos que acontecem a partir destas experiências. A quantidade e qualidade destas experiências é que podem predispor uma prática profissional com manejo seguro. A avaliação também deve ser vista como uma oportunidade de aprendizado, e não apenas como mera formalidade ou instrumento punitivo. 
Além disso, assim como a sociedade que se encontra cada vez mais adoentada emocionalmente, os estudantes de medicina que já fazem parte deste contexto geral, ainda carregam cargas excessivas de responsabilidade geradas ao longo do curso, que debilitam ainda mais o seu próprio estado. Essa debilidade emocional, quando em contato com os processos de transferência, contratransferência e projeção que ocorrem na interação com os pacientes em acompanhamento na saúde mental, sem o devido suporte emocional, corroboram para uma piora do quadro e no aspecto formativo, afastam o acadêmico do interesse pela área de saúde mental, e consequentemente dificultam $\circ$ aprendizado. Nesse sentido, é imperativo o acompanhamento psicopedagógico dos estudantes de medicina, em especial durante as atividades de saúde mental do curso. O próprio processo de acompanhamento emocional dos acadêmicos pode ainda quebrar a dificuldade encontrada quanto a subjetividade da saúde mental, pelo próprio processo de autoconhecimento e experiência vivida.

E por fim, é importante ressaltar que a pesquisa apresenta limitações, mas que pode servir de reflexão para outras instituições, principalmente quanto a necessidade de realizar diagnósticos do ambiente acadêmico e da própria estrutura curricular, e desenvolvimento das atividades na área de saúde mental.

\section{REFERÊNCIAS}

1. Picoli RP et al. Competências Propostas no Currículo de Medicina: Percepção do Egresso. Revista Brasileira de Educação Médica. 2017; 41(4):525-532.

2. Amarante P. Saúde Mental e Atenção Psicossocial. Rio de Janeiro: Editora Fiocruz; 2007. 120p.

3. Minayo MCS. O desafio do conhecimento: pesquisa qualitativa em saúde. 14a ed. São Paulo: Hucitec, 2014. 407p.

4. Bardin L. Análise de conteúdo. Lisboa: Edições 70; 2011. 229p. 
5. Luckesi CC. Avaliação da aprendizagem: componente do ato pedagógico. 1aㅡ ed. São Paulo: Cortez; 2011.

6. Zimmermann $\mathrm{MH}$ et al. O Professor e a arte de avaliar no Ensino Médico de uma Universidade no Brasil. Revista Brasileira de Educação Médica. 2019; 43(3):5-15.

7. Torres AR et al. Ensinando a Anamnese Psiquiátrica para Estudantes de Medicina através da Inversão de Papéis: Relato de Experiência. Revista Brasileira de Educação Médica. 2019; 43(2):200-207.

8. Brasil. Ministério da Educação. Conselho Nacional de Educação. Câmara de Educação Superior. Resolução CNE/CES n. 3, de 20 de junho de 2014. Institui Diretrizes Curriculares Nacionais do Curso de Graduação em Medicina e dá outras providências. Brasília: Ministério da Educação; 2014.

9. World Health Organization. The global burden of disease: 2004 update [Internet]. Geneva: WHO, $2008 . \quad$ Disponível em: http://www.who.int/healthinfo/global_burden_disease/GBD_report_2004u pdate_full.pdf. [Acesso: em 2019 maio 21].

10. Santos EF, Siqueira MM. Prevalência dos transtornos mentais na população adulta brasileira: uma revisão sistemática de 1997 a 2009. Jornal Brasileiro de Psiquiatria. 2010; 59(3):238-246.

11. Voltmer $\mathrm{E}$ et al. Study-related health and behavior patterns of medical students: A longitudinal study. Med Teach. 2010; 32(10):e422-8.

12. Costa GPO et al. Enfrentamentos do Estudante na Iniciação da Semiologia Médica. Revista Brasileira de Educação Médica. 2018; 42(2):79-88. 
13. Maslach C, Jackson SE, Leiter MP. The Maslach Burnout Inventory, Manual. Consulting Psycologists. Palo Alto: University of California; 1996.

14. Mori MO, Valente TCO, Nascimento LFC. Síndrome de Burnout e rendimento acadêmico em estudantes da primeira à quarta série de um curso de graduação em medicina. Revista Brasileira de Educação Médica. 2012; 36(4):536-540.

15. Figueiredo FP et al. Implementation of a Mental Health internship in a higher education institution. Interface. 2019;23(supl. 1):e170898.

16. Arón A, Llanos M. Desgaste profesional. In A. Arón, Violencia en la familia. Programa de intervención en red: la experiencia de San. Santiago: Galdoc; 2001. p. 67-103

17. Vio CG et al. Análisis psicométrico de la escala de conductas de autocuidado para psicólogos clínicos. Revista Latinoamericana de Psicología. 2011; 43(2) 319-328.

18. Wolf C, Falcke D. A contratransferência na clínica psicanalítica contemporânea. Análise Psicológica. 2011; 2(29): 201-214.

19. Nogueira C. Um olhar sociológico sobre o privilégio epistémico da biomedicina: desconstruindo a metanarrativa. Saúde e Sociedade. 2018; 27(4):1019-1032.

20. Balduino PM et al. A perspectiva do paciente no roteiro de anamnese: o Olhar do estudante. Revista Brasileira de Educação Médica. 2012; 36(3)335-342. 